\title{
Corrosion Modeling of Aluminum/Stainless Steel under Atmospheric Conditions in Salt Solution
}

\author{
${ }^{1}$ Ali Nasir Khalaf and ${ }^{2}$ Raheem K. Al-Sabur \\ ${ }^{1}$ Department of Chemical Engineering, College of Engineering, \\ ${ }^{2}$ Department of Mechanical Engineering, College of Engineering, University of Basrah, Basrah, Iraq \\ alinasserey@yahoo.com
}

\begin{abstract}
The objective of this research is to study the corrosion of aluminum/stainless steel connections in atmospheric conditions at concentrations of salt loads from $0.001-0.005 \mathrm{~kg} / \mathrm{m}^{2}$ and underexposure to temperature range from $27-88^{\circ} \mathrm{C}$. The results show that corrosion rates are generally, proportional to salt loading but at low salt concentrations, the corrosion rates are very high especially at low temperatures. The results also showed that the rate of corrosion decreases as the temperature rises because the high temperature causes a drop in the relative humidity.
\end{abstract}

Key words: Aluminum, corrosion, modeling, salt solution, comsol, temperature

\section{INTRODUCTION}

Corrosion is one of the most important problems facing the industry and equipment, causing great economic losses that must be avoided and reduced. All manufactured alloys from natural raw materials have higher levels of energy and corrosion phenomena returns them to low energy levels similar to the original state in which the metal was found in the natural. All substances aim to stabilize by achieving a low energy state. Corrosion is a natural process that provides a way for substances to lower their energy state, most metals, except for very noble metals will corrode under normal environmental conditions (Roberge, 2008). The aluminum and stainless steel combination are one of the most useful applications such as in modern aircraft and bicycles. These applications facing the galvanic forms of corrosion when exposed to environmental conditions. Galvanic corrosion is a type of corrosion and has the same corrosion conditions for submerged objects surrounded by a thin layer of electrolyte which does not exceed the thickness of fewer than $100 \mu$. The corrosion of surfaces exposed to atmospheric conditions is weak and can only occur in the presence of water or dissolved solids or gases (Cole et al., 2004). Many different variables are affecting the thin electrolyte layer formation, composition and destruction which are leading to the difficult understanding of the individual processes kinetics. Furthermore, the buildup of corrosion products may lead to a sudden change of a chemically controlled process to mass-transport controlled which means the kinetics can change rapidly (Linares et al., 2006). Many extensive studies were made of aluminum and aluminum alloys under field atmospheric exposure conditions such as a study of enhancing or control corrosion rates according to the effects of exposure factors and environmental severity. The common fact of most of these studies indicates higher corrosion rates with higher salt deposition rates (Sun et al., 2009; Gonzalez et al., 2002; Vera et al., 2006). It is often difficult to understand the reliance of corrosion on one single severity factor since the atmospheric field exposures are affected by a wide range of environmental factors such as salt deposition rates, humidity, temperature, $\mathrm{pH}$, ozone and other pollutants. Many studies have studied galvanic and micro-galvanic corrosion in aluminum alloys including computational modeling (Perko, 2009).

The studies of galvanic corrosion evaluation of aluminum alloys under atmospheric conditions are limited. Due to the existence of difficult factors such as relative humidity, loading density, the metals area ratio, etc., led to believe that the computational work is an active way for the atmospheric corrosion prediction better than laboratory experiments.

The main objective of this study is to build the preliminary model to examine numerically the electrochemical potential and the corrosion current density due to the galvanic coupling between aluminum alloy and steel in the presence of a thin $\mathrm{NaCl}$ solution layer to simulate the atmospheric corrosion. The model

Corresponding Author: Ali Nasir Khalaf, Department of Chemical Engineering, College of Engineering, University of Basrah, Basrah, Iraq, alinasserey@yahoo.com 
geometry was a simple one consisting of the domain of $\mathrm{NaCl}$ solution and the boundaries of aluminum and steel surfaces exposed to the solution.

Corrosion in seawater: Seawater is a solution of about $3.5 \%$ dissolved salts like $\mathrm{NaCl}$ and about $96.5 \%$ water. Corrosion is a metal degradation when it is in contact with a solution of Sodium Chloride $(\mathrm{NaCl})$ containing aqueous oxygen. Seawater salinity usually varies between 3.1 and $3.8 \%$ while the $\mathrm{pH}$ value is around 7.5-8.4. This value can decrease or increase depending upon acidification and higher Hydroxide (OH-) production (Groysman, 2010). Seawater electrical conductivity is proportional to increasing of salinity and temperature, it is usually between 2.0 and $5.0 \mathrm{~S} / \mathrm{m}$ (Roberge, 2008). Based on the electrochemical potential voltage tables, aluminum can be considered as a anode in the galvanic cell while carbon steel takes the role of the cathode. Any combination or contact between the two metals leads to aluminum corrosion very quickly. Although, electrolyte corrosion occurs in the presence of electrolytic solutions such as sodium chloride, it can also occur in the absence of electrolytic solutions such as the presence of oxygen, chlorine or water (Newman and Thomas-Alyea, 2004). Galvanic corrosion is a simultaneously redox-reaction process where there can be multiple anodic and cathodic reactions occurring simultaneously. Mostly or totally, reduction reactions take place on the cathode while oxidation reaction occurs on the anode (Pour-Ghaz et al., 2009).

Anodic reaction: The dissolution of metal is the main anodic reaction is which involves the flow of electrons from the anode and can cause corrosion to occur. For aluminum, the anodic reaction is:

$$
\mathrm{Al}(\text { solid }) \rightarrow \mathrm{Al}^{3+}+3 \mathrm{e}
$$

Cathodic reaction: The cathodic reaction is the consuming process of released electrons in the anodic reaction. This reaction depends on environmental factors and the metals involved. Both anodic reaction and cathodic reactions have to exactly balance each other. Sometimes in neutral electrolytes, the aluminum anodic corrosion produces enough energy to the ionic decomposition of water, directly on the cathodic site:

$$
2 \mathrm{H}_{2} \mathrm{O}(\text { liquid })+2 \mathrm{e}^{-} \rightarrow \mathrm{H}_{2} \text { (gas) }+2 \mathrm{OH}^{-}
$$

The oxygen reduction is the predominant reaction in neutral or acidic solutions exposed to atmospheric conditions:

$$
\mathrm{O}_{2}+2 \mathrm{H}_{2} \mathrm{O}+4 \mathrm{e}^{-} \rightarrow 4 \mathrm{OH}^{-}
$$

Hydrogen reduction may also occur in acidic solutions that release hydrogen gas by a cathode reaction:

$$
3 \mathrm{H}^{*}+2 \mathrm{e}^{-} \rightarrow \mathrm{H}_{2}
$$

In general, the summation of anodic and cathodic reactions represents the corrosion reaction. For aluminum components, the two most likely combined reactions are the following:

\section{Splitting of water:}

- Anodic reaction: $\mathrm{Al}\left(\right.$ solid) $\rightarrow \mathrm{Al}^{3+}+3 \mathrm{e}$

- Cathodic reaction: $2 \mathrm{H}_{2} \mathrm{O}($ liquid $)+2 \mathrm{e}^{-} \rightarrow \mathrm{H}_{2}+2 \mathrm{OH}^{-}$

- Overall corrosion reaction: $\mathrm{Al}+2 \mathrm{H}_{2} \mathrm{O}($ liquid $) \rightarrow$ $\mathrm{Al}(\mathrm{OH})_{3}+3 \mathrm{H}_{2}$

\section{Reduction of oxygen:}

- Anodic reaction: $\mathrm{Al}($ solid $) \rightarrow \mathrm{Al}^{3+}+3 \mathrm{e}$

- Cathodic reaction: $\mathrm{O}_{2}+2 \mathrm{H}_{2} \mathrm{O}+4 \mathrm{e}^{-} \rightarrow 4 \mathrm{OH}^{-}$

- Overall corrosion reaction (balanced): $4 \mathrm{Al}+3 \mathrm{O}_{2}+$ $6 \mathrm{H}_{2} \mathrm{O}($ liquid $) \rightarrow 4 \mathrm{Al}(\mathrm{OH})_{3}$

Also, chemical reactions would occur, for example:

$$
\begin{aligned}
& \mathrm{Fe}^{+2}+\mathrm{H}_{2} \mathrm{O} \rightarrow \mathrm{FeOH}^{+}+\mathrm{H}^{+} \\
& \mathrm{Fe}^{+2}+2 \mathrm{Cl} \rightarrow \mathrm{FeCl}_{2}
\end{aligned}
$$

The product from both reactions is Aluminum Hydroxide $\mathrm{Al}(\mathrm{OH})_{3}$ which eventually lead to Aluminum corrosion. $\mathrm{Al}(\mathrm{OH})_{3}$ is a gelatinous material deposited on the surface of the material which crystallizes later and dries up as a white solid material (Inzelt, 2006).

\section{MATERIALS AND METHODS}

Computational model: The galvanic corrosion differential equations were solved using COMSOL multiphysics. Figure 1 shows the model geometry which was used in this study. The model under consists of two co-planar electrodes composed of an anode (aluminum) and the cathode (steel). In simulation it is represented boundaries of two metals (1,2) and electrolyte (4) while the 


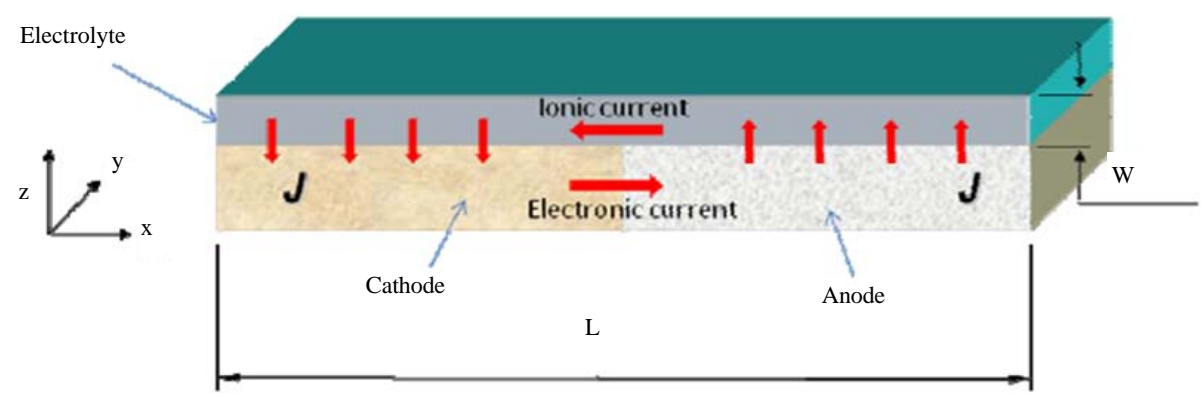

Fig. 1: Schematic representation of galvanic corrosion in the presence of thin film electrolytes where $\mathrm{w}<<\mathrm{L}$

boundaries $(3,5)$ were insulators. The electrolyte is a solution $(\mathrm{NaCl})$ with varying concentrations, the thickness of electrolyte $\delta$ should be small to simulate atmospheric conditions. In this study, the minimum value of $\delta$ was $0.2 \mathrm{~mm}$ because the simulation would not converge when the $\delta$ was $<0.2 \mathrm{~mm}$. The thickness of the thin electrolyte was calculated from the relation between salt Loading Density (LD) and Relative Humidity (RH). The electrolyte dimensions are $12 \times 12 \mathrm{~mm} \mathrm{x}$ and $\mathrm{y}$ directions, respectively while the $\mathrm{z}$-direction is variable.

Governing equations: The application mode of Nernst-Planck with electroneutrality is used to describe the concentration profile of chemical species as a result of ionic migration and diffusion. The simulation assumes steady-state conditions and no convection under thin electrolyte, the terms for migration and diffusion of species were considered:

$$
\frac{\partial c_{i}}{\partial t}=\nabla \cdot\left(D_{i} \nabla c_{i}-z_{i} F \frac{D_{i}}{R T} \nabla \varnothing\right)=R_{i}
$$

Where:

$c_{i}=$ The concentration of the species $\mathrm{i}\left(\mathrm{mol} \cdot \mathrm{m}^{-3}\right)$

$D_{i}=$ The Diffusion coefficient of the species I

$\mathrm{z}_{\mathrm{i}}=$ The charge number of the species I

$\mathrm{F}=$ The Faraday constant $\left(96500^{\circ} \mathrm{C} \cdot \mathrm{mol}^{-1}\right)$

$\varnothing=$ The potential in the domain (in the solution)

$\mathrm{R}_{\mathrm{i}}=$ The production term which represents the flux of species due to reactions in the domain $\left(\mathrm{mol} \cdot \mathrm{m}^{-2} \cdot \mathrm{s}^{-1}\right)$

This equation introduces $\mathrm{n}+1$ variable which is the concentration of each dissolved species and the potential, the electroneutrality equation was used to eliminate the variable and solve these equations:

$$
\sum \mathrm{Z}_{\mathrm{i}} \mathrm{C}_{\mathrm{i}}=0
$$

A cathodic diffusion plateau and the Buttler-Volmer equations are used to represent the current density as the boundary condition. For aluminum side:

$$
\begin{aligned}
& \mathrm{i}_{\mathrm{A} 10} \exp \left(\frac{\mathrm{E}_{\mathrm{A} 10}-\left(\mathrm{V}_{\mathrm{m}}-\mathrm{V}\right)}{-\propto_{\mathrm{A} 1 \mathrm{a}}}\right)+\mathrm{i}_{\mathrm{ALLim}} \mathrm{i}_{\mathrm{A} 10} \\
& i_{A 1}=\frac{\exp \left(\frac{\left.\frac{\alpha_{A 1 c} F\left(E_{A 10}-\left(V_{m}-V\right)\right)}{R}\right)}{T}\right)}{i_{A 1 L i m}+i_{A 10} \exp \left(\frac{\frac{\alpha_{A 1 c} F\left(E_{A 10}-\left(V_{m}-V\right)\right)}{R}}{T}\right)} \\
& \mathrm{i}_{\mathrm{A} 10}=\mathrm{D}_{\mathrm{O} 2} * \frac{\mathrm{C}_{\mathrm{O} 2}}{\delta^{*} 0.00000259}
\end{aligned}
$$

For steel side:

$$
i_{\mathrm{Fe}=\mathrm{FeLim}} \mathrm{i}_{\mathrm{Fe} 0} \frac{\exp \left(\frac{\left.\frac{\alpha \mathrm{F}_{\mathrm{ec}} \mathrm{F}\left(\mathrm{E}_{\mathrm{Fe} 0}-\left(\mathrm{V}_{\mathrm{m}}-\mathrm{V}\right)\right)}{\mathrm{R}}\right)}{\mathrm{T}}\right)}{\mathrm{i}_{\mathrm{Felim}}+\mathrm{i}_{\mathrm{Fe} 0} \exp \left(\frac{\frac{\propto \mathrm{F}_{\mathrm{ec}} \mathrm{F}\left(\mathrm{E}_{\mathrm{AFe} 0}-(\mathrm{Vm}-\mathrm{V})\right)}{\mathrm{R}}}{\mathrm{T}}\right)}
$$

where, $i_{A 10}, i_{F e 0}$ represents the current density exchange for aluminum and steel sides, respectively. $i_{\text {AlLim }}, i_{\text {FeLim }}$ is the current density limiting of cathodic reaction on $\mathrm{Al}$ and steel due to the oxygen diffusion. $\mathrm{E}_{\mathrm{Al} 0,} \mathrm{E}_{\mathrm{Fe} 0}$ are corrosion potential of $\mathrm{Al}$ and steel. $\alpha_{\mathrm{Al},}, \alpha_{\mathrm{Fec}}$ are cathodic transfer coefficient of $\mathrm{Al}$ and steel. $\alpha_{\mathrm{Ala}}$ is anodic transfer coefficient of $\mathrm{Al}$ while the anodic reaction of steel was ignored, since, the effect of it on galvanic corrosion for $\mathrm{Al}$ is negligible. $\mathrm{R}$ is gas constant $(\mathrm{J} / \mathrm{mol} / \mathrm{K})$ and $\mathrm{T}$ is Temperature $(\mathrm{K})$. $\mathrm{V}$ is the potential of the metal $(\mathrm{V})$ and $\mathrm{Vm}$ is the potential in the solution (V), its value set as 0 in the current study. In this study, $\mathrm{V}_{\mathrm{m}}$ was set to 0 . Table 1 shows the electrochemical parameters which are used in the model. 
Table 1: Electrochemical parameters

\begin{tabular}{lll}
\hline Symbol & Variable & Values $/$ Units \\
\hline E_cond & Electrolyte conductivity & $24.4(\mathrm{~S} / \mathrm{m})$ \\
D_O $_{2}$ & $\begin{array}{l}\text { Diffusion coeff. for } \mathrm{O}_{2} \text { in the } \\
\text { electrolyte at } 20^{\circ} \mathrm{C}\end{array}$ & $1.97 \mathrm{E}-09\left(\mathrm{~m}^{2} / \mathrm{sec}\right)$ \\
i0_Al & Exchange current density, & $0.16681\left(\mathrm{~A} / \mathrm{m}^{2}\right)$ \\
& Al surface & $-1.4949(\mathrm{~V})$ \\
$\mathrm{Ac} \_\mathrm{Fe}$ & Tafel slope, Fe surface & $0.1307(\mathrm{~V})$ \\
$\mathrm{Aa} \_\mathrm{Al}$ & Tafel slope, Al surface & $-0.952(\mathrm{~V})$ \\
Eeq_Al & Equilibrium potential, Al surface \\
i0_Fe & Exchange current density, Fe surface & $5.6 \mathrm{e}-2\left(\mathrm{~A} / \mathrm{m}^{2}\right)$ \\
Eeq_Fe & Equilibrium potential, Fe surface & $-0.535(\mathrm{~V})$ \\
\hline
\end{tabular}

In bulk electrolyte, the galvanic corrosion was controlled by the reduction reaction of oxygen on the steel surface. The limiting current density, $\mathrm{i}_{\text {FeLim }}$ is changed as a function of the electrolyte thickness, increasing when the thickness of the electrolyte is thin because more oxygen dissolved in solution could reach the surface of steel more easily though the thinner diffusion layer.

In general, the reduction reaction of $\mathrm{O}_{2}$ on the steel side was controlled the galvanic corrosion. The $i_{\text {FeLim }}$ is increasing when the electrolyte layer thickness is thin. In the diffusion layer any more oxygen dissolved in solution could reach the steel surface easily. The limiting current density, $\mathrm{i}_{\mathrm{FeLim}}$ is representing by the following equation:

$$
\begin{gathered}
\mathrm{i}_{\mathrm{FeLim}}=\frac{\mathrm{zFD} \mathrm{O}_{\mathrm{O} 2} \mathrm{C}_{\mathrm{O}}}{\delta} \\
\delta=\mathrm{LD}_{\mathrm{NaCl}} * 2.15^{*} 10^{-11} * \exp \left(6.03^{*} 10^{-4} * \mathrm{RH}\right) \\
\mathrm{D}_{\mathrm{O} 2}=-0.14164^{*} 10^{-3} \mathrm{cNaCl}\left[\frac{\mathrm{m}^{3}}{\mathrm{~mol}}\right]+2.0511^{*} 10^{-9}\left[\frac{\mathrm{m}^{3}}{\mathrm{~s}}\right] \\
\mathrm{C}_{\mathrm{O} 2}=0.0003^{*} \exp \left(6.59^{*} \mathrm{RH}\right) \mathrm{mol} \frac{\mathrm{mol}}{\mathrm{m}^{3}}
\end{gathered}
$$

Where:

$\mathrm{D}_{\mathrm{O} 2}=$ The oxygen Diffusion coefficient

$\mathrm{C}_{02}=$ The oxygen Concentration

$\mathrm{RH}=$ The Relative Humidity

$\mathrm{LD}_{\mathrm{NaCl}}=$ The salt Loading in $\mathrm{gm} / \mathrm{m}^{2}$

In this study, $\mathrm{D}_{\mathrm{O} 2}=1.27 \times 10-9\left(\mathrm{~m}^{2} \cdot \mathrm{s}^{-1}\right)$ and $\mathrm{C}_{02}=$ $2.58 \times 10^{-1}\left(\mathrm{~mol}^{-3}\right)$ at $25^{\circ} \mathrm{C}$ were used. $\delta$ is the diffusion layer thickness which is can be assumed as the same value of electrolyte thickness when it is very thin $(\leq 0.2 \mathrm{~mm})$ such as under atmospheric conditions. Arrhenius equation type is used to describe the effect of temperature on the oxygen diffusion coefficient:

$$
\frac{\mathrm{D}_{\mathrm{O} 2 \mathrm{~T}}=\mathrm{D}_{\mathrm{O} 2} \exp (-\mathrm{E})}{\mathrm{RT}}
$$

Where:

$\mathrm{E}=$ Activation Energy for oxygen diffusion

$\mathrm{R}=$ Universal gas constant

$\mathrm{T}=$ Absolute Temperature

Values for the activation energy of oxygen diffusion can be found in kinds of literature (Page and Lambert, 1987; Stroe and Janssen, 1993). The relative humidity is calculated from the following Eq. 10:

$$
\begin{gathered}
\mathrm{RH}=\frac{\mathrm{PW}}{\mathrm{Pws} * 100} \\
\mathrm{P}_{\mathrm{ws}}=0.006[\mathrm{bar}] * 10^{\mathrm{Td} * \frac{7.3379[\mathrm{C}]}{\mathrm{Td}+229.39[\mathrm{c}]}}
\end{gathered}
$$

where, $\mathrm{Td}$ and $\mathrm{Pw}$ are the dry temperatures and saturation pressure $25^{\circ} \mathrm{C}$ and 1 bar, respectively.

\section{RESULTS AND DISCUSSION}

Figure 2 shows the potential distribution through the electrolyte layer at $30^{\circ} \mathrm{C}$ for different combinations of salt loading 0.001 and 0.005 . At low temperature and low salt loading, the electrolyte potential values at the surface were $0.87 \mathrm{~V}$ while at the same temperature and for salt loading 0.005 , the potential was $0.75 \mathrm{~V}$. The potential distribution varies with the location along with the two metals but it is more severe at the point of contact.

Figure 3 and 4 show the local current density of the electrode reactions for a salt load of 0.005 and 0.002 for various temperatures. The cathodic currents reach a maximum value close to $\mathrm{x}=0$ at a magnitude that is significantly affected by temperature. This is due to a changing limiting current density for oxygen reduction. As the film thickness grows, the electrolyte transport length for oxygen increases in combination with an increased oxygen solubility and diffusivity at higher temperatures as expected from Eq. 7.

Figure 5 shows the maximum anodic currents for various salt load densities and different temperatures. For all salt loads, a current density is seen within the range of $20-100 \mathrm{~A} / \mathrm{m}^{2}$. Looking at the maximum cathodic currents in Figure 5 it is seen that the maximum oxygen currents are about one order of magnitude smaller than the anodic currents but that they follow the same trend with a similar current density at higher temperatures.

These currents are very close to the limiting current densities for oxygen reduction. Finally, Fig. 6 shows the average anode current density which gives us a measure of the total corrosion rate of the sample, for various temperatures and salt load densities. The higher current 
(a)

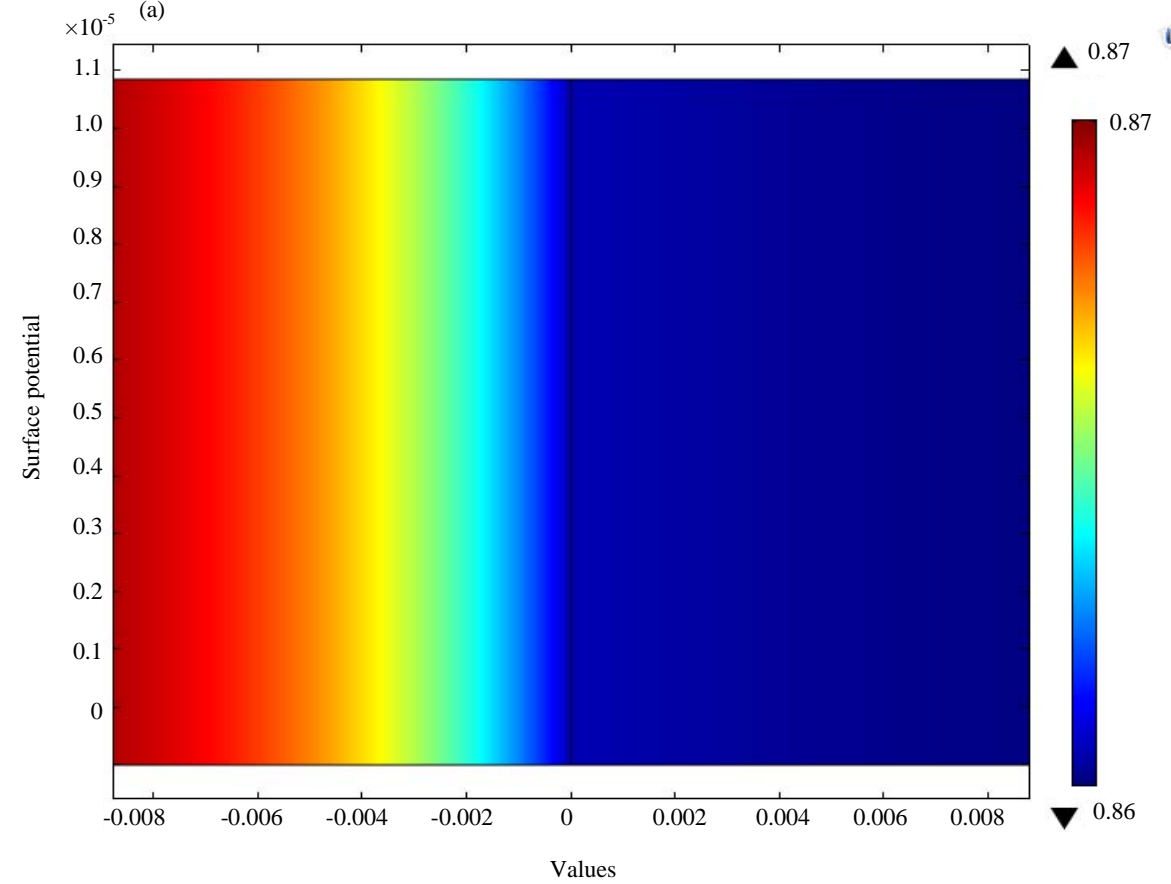

(b)

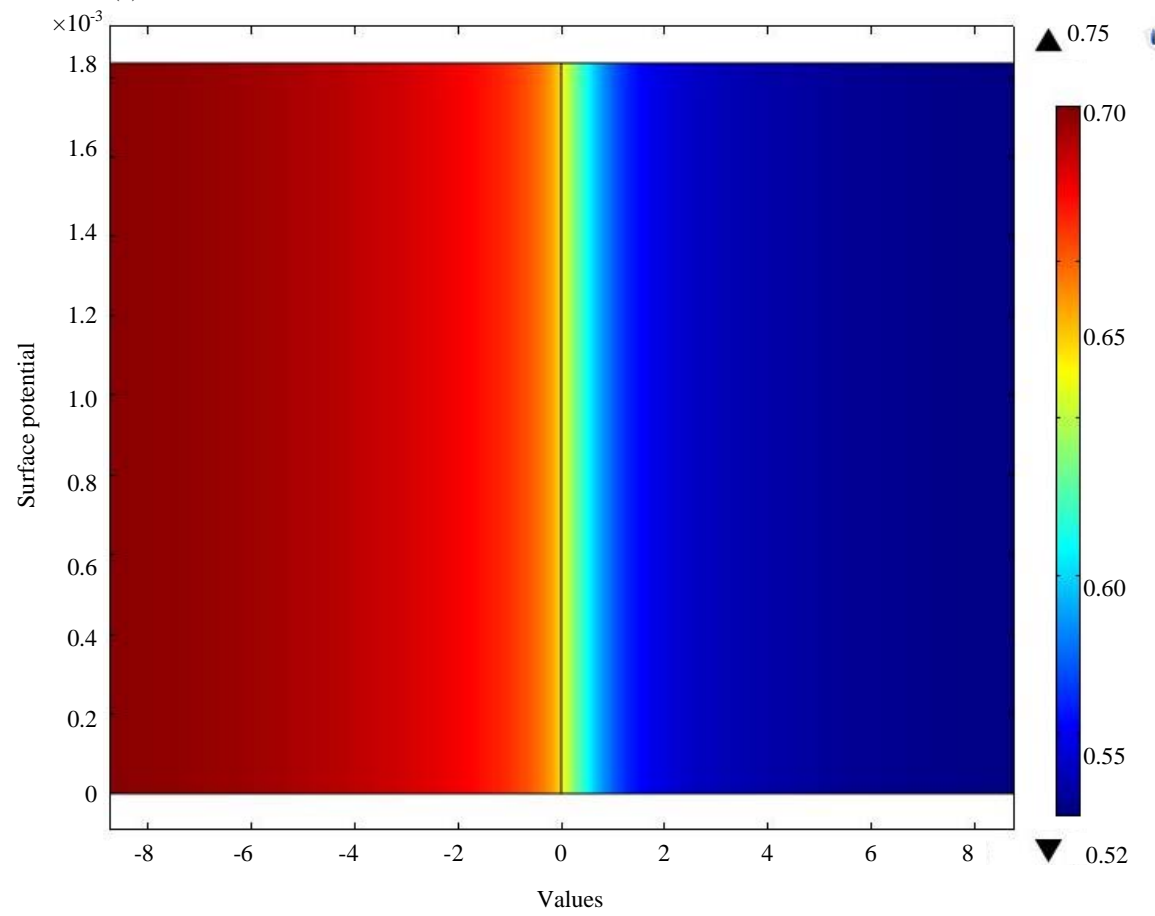

Fig. 2: Surface potential at $30^{\circ} \mathrm{C}$ with different salt loading: a) $1: \mathrm{T}=30, \mathrm{LD}=0.001$; Surface electrolyte potential (V) and b) $\mathrm{LD}=0.005, \mathrm{~T}=30$; Surface electrolyte potential $(\mathrm{V})$

is found at low temperatures for all salt loading. At the interface between $\mathrm{Al}$ and $\mathrm{Fe}$, the maximum anodic current density was found near the contact point. This current density distribution supports the findings in Fig. 2.
Although, both anode and cathode areas are almost equal, the maximum local current densities are higher at the interface (Fig. 3 and 4). The atmospheric galvanic corrosion current mostly independent of the size of the 


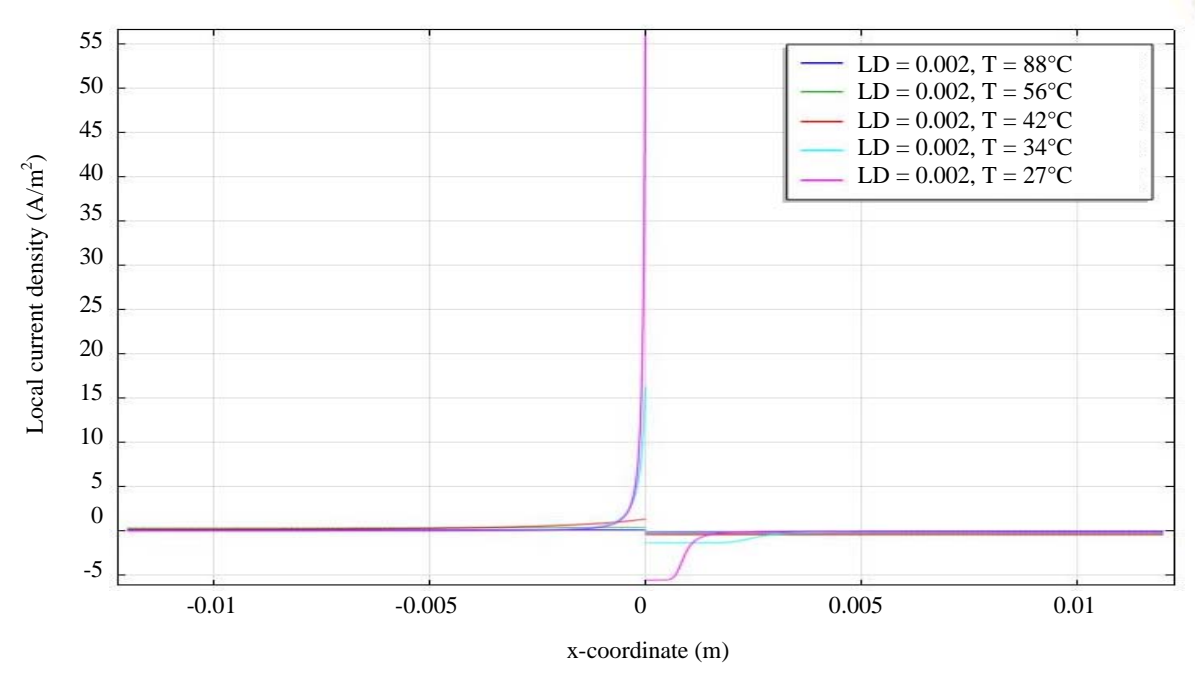

Fig. 3: Local current densities along the metal surface at a salt loading of $0.002 \mathrm{~g} / \mathrm{m}^{2}$ and temperature from $27-88^{\circ} \mathrm{C}$; Line graph: local current density $\left(\mathrm{A} / \mathrm{m}^{2}\right)$

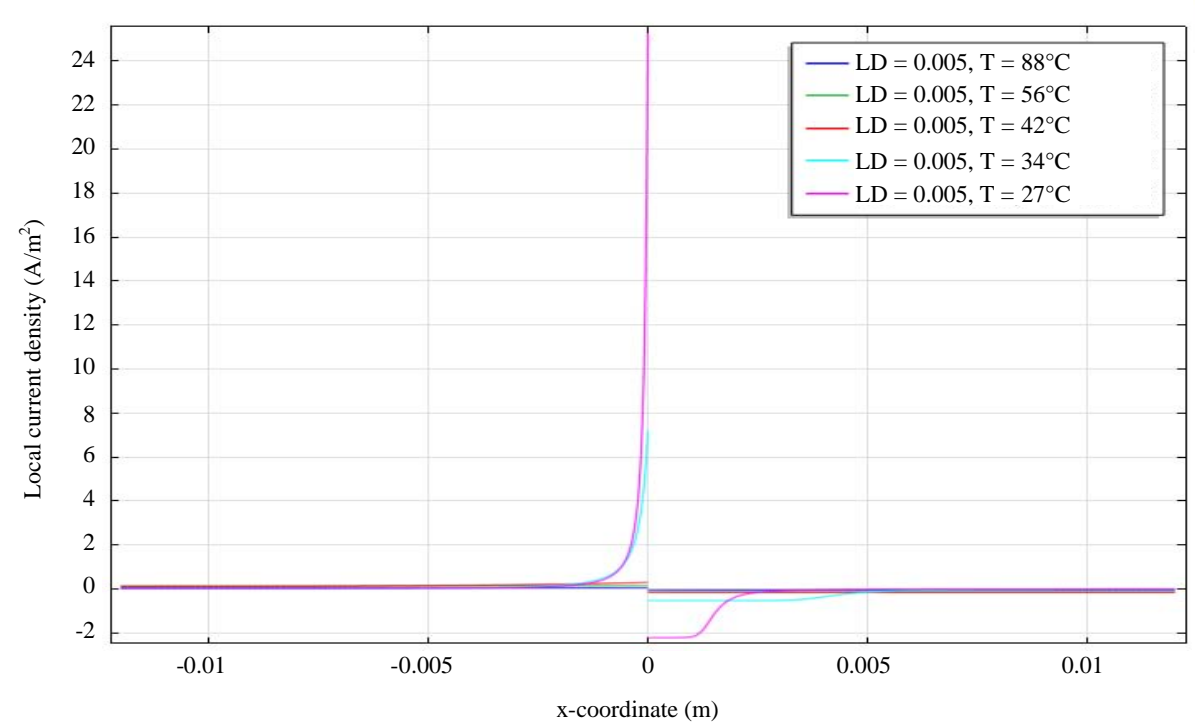

$\square$

Fig. 4: Local current densities along the metal surface at a salt loading of $0.005 \mathrm{~g} / \mathrm{m}^{2}$ and temperature from $2788^{\circ} \mathrm{C}$; Line graph: local current density $\left(\mathrm{A} / \mathrm{m}^{2}\right)$

anode, this supports the assumption that atmospheric galvanic corrosion is local and always occurs near the contact area between the two materials.

The average cathode density current as shown in Fig. 7 shows a similar pattern for the maximum current density. The similarity between them, despite the difference in temperature, confirms that the process of corrosion occurs under the influence of cathodic reaction. The limiting step of the total corrosion current is the rate of cathodic reaction. The value of the maximum anode currents rate is greater than the average current density.
This represents the fact that galvanic corrosion is influenced by atmospheric conditions even when current rates are low.

Relative humidity in the atmosphere around the metal plays an important role and directly affects the amount of water on the surface of the metal, specifically the thickness of the water layer on the metal. Figure 8 shows that the metal erosion rate in the atmosphere increases with increasing relative humidity during exposure to the atmosphere. The variations of current density with humidity for different salt loading have a much greater 


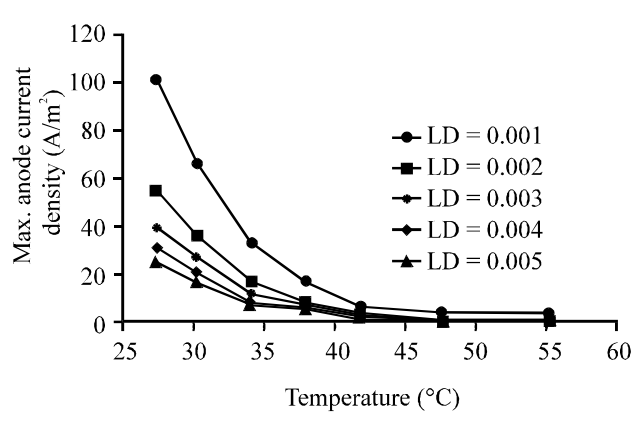

Fig. 5: Maximum oxidation anodic current density on the aluminum surface for different temperature and salt loading

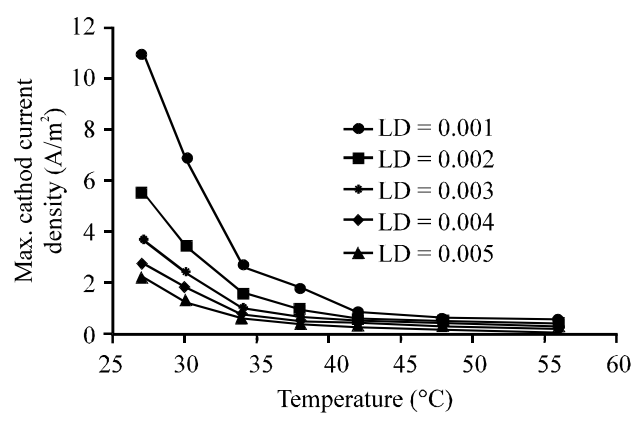

Fig. 6: Maximum reduction cathodic current densities on the steel surface for different temperature and salt loading

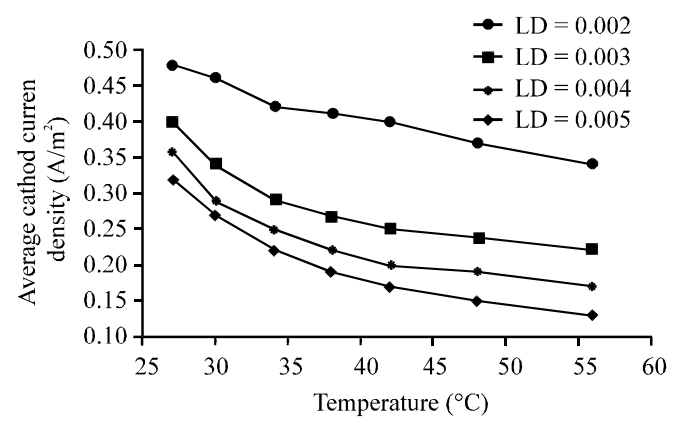

Fig. 7: Average current densities on the aluminum surface for different temperature and salt loading

effect on the total galvanic corrosion rate because of the dominating control step is the diffusion of oxygen through the electrolyte layer which has higher values at low temperatures (higher humidity). The local current density and the corrosion rate increased with the increasing relative humidity and salt loading, this trend was clear for all salt loading.

As shown in Fig. 8, the current rates are significantly higher when the relative humidity values above $50 \%$ while corrosion rates are low at low humidity values. The topical

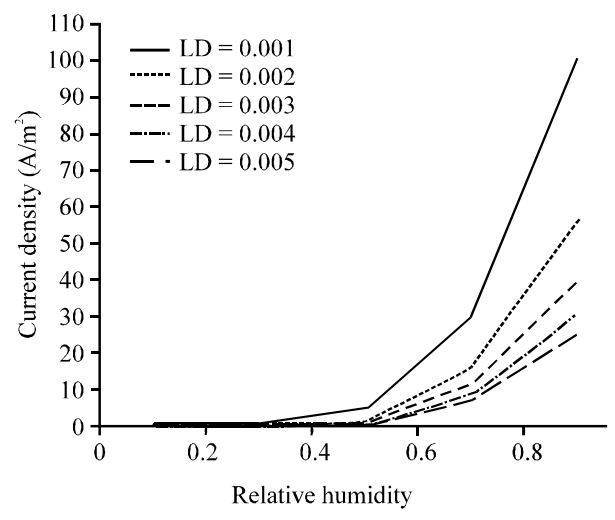

Fig. 8: Average current densities on the aluminum surface for different temperature and salt loading

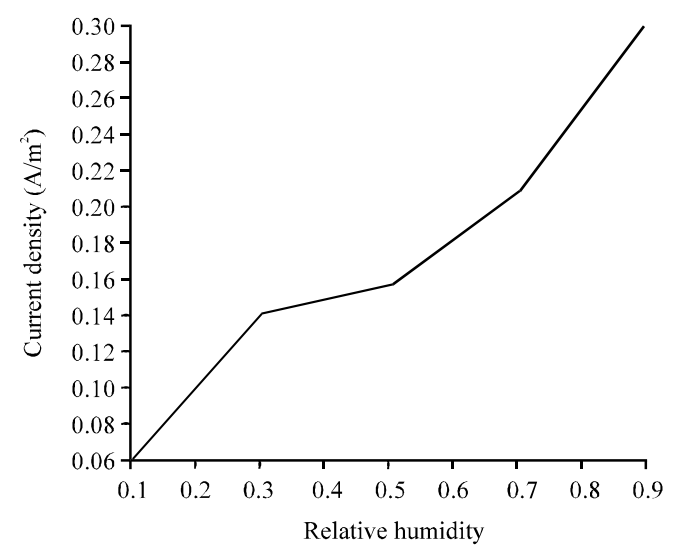

Fig. 9: Average current densities on the aluminum surface for different temperature and salt loading

corrosion rate is significant at low salt loading $(0.001)$ because the electrolyte layer is very thin and represents the main resistance. At higher concentrations of salt as shown in Fig. 9, the thickness of the layer is significant, so, the mechanism of oxygen diffusion through the thick electrolyte layer is the limiting step of corrosion mechanism. As the film thickness grows, the electrolyte transport length for oxygen increases in combination with an increased oxygen solubility and diffusivity for higher relative humidity. In this case, even at higher humidity range, the rate of corrosion is lower than the rate for atmospheric conditions. The highest galvanic corrosion rate is predicted at low salt loading. The electrolyte layer is very thin at low salt load density and the main controlling mechanism is the resistance of the electrolyte solution.

\section{CONCLUSION}

This study focuses on the examination of the corrosion for contacting between aluminum and stainless 
steel. The conclusion from the comparison of the salt loading and temperature is that the corrosion rate is very high at low temperatures for all ranges of salt loading. At higher temperatures, the corrosion rate is decreased $\left(>45^{\circ} \mathrm{C}\right)$. The highest galvanic corrosion rate is predicted at low salt loading. The average anode current density which gives us a measure of the total corrosion rate of the sample is very high at low salt loading increasing the salt loading does not affect the corrosion rate because of the presence of thick electrolyte layer which slow oxygen solubility and diffusivity through the film.

\section{REFERENCES}

Cole, I.S., W.D. Ganther, J.D. Sinclair, D. Lau and D.A. Paterson, 2004. A study of the wetting of metal surfaces in order to understand the processes controlling atmospheric corrosion. J. Electrochem. Soc., 151: B627-B635.

Gonzalez, J.A., M. Morcillo, E. Escudero, V. Lopez and E. Otero, 2002. Atmospheric corrosion of bare and anodized Aluminium in a wide range of environmental conditions, Part I: Visual observations and gravimetric results. Surf. Coat. Technol., 153: 225-234.

Groysman, A., 2010. Corrosion for Everybody. Springer, Netherlands, ISBN:9789048134946, Pages: 368.

Inzelt, G., 2006. Standard, Formal and other Characteristic Potentials of Selected Electrode Reactions. In: Encyclopedia of Electrochemistry: Inorganic Electrochemistry, Bard, A.J., M. Stratmann, F. Scholz and C.J. Pickett (Eds.). Wiley, ?Hoboken, New Jersey, USA., ISBN:9783527317004, pp: 17-77.
Linares, L., N. Taborda, L. Zambrano and O. Perez, 2006. Failures analysis by corrosion in power conductors of Aluminum alloys in coastal-lacustrian environments. Proceedings of the 2006 IEEE/PES Transmission \& Distribution Conference and Exposition: Latin America, August 15-18, 2006, IEEE, Caracas, Venezuela, pp: 1-6.

Newman, J. and K.E. Thomas-Alyea, 2004. Electrochemical Systems. 3rd Edn., Wiley-Interscience, ?Hoboken, New Jersey, ISBN-13:978-0471477563, Pages: 672.

Perko, H.A., 2009. Corrosion and Life Expectancy. In: Helical Piles: A Practical Guide to Design and Installation, Perko, H.A. (Ed.). John Wiley \& Sons, Hoboken, New Jersey, USA., ISBN:978-0-470-40479-9, pp: 295-324.

Pour-Ghaz, M., O.B. Isgor and P. Ghods, 2009. The effect of temperature on the corrosion of steel in concrete Part 2: Model verification and parametric study. Corros. Sci., 51: 426-433.

Roberge, P.R., 2008. Corrosion Engineering: Principles and Practice. McGraw-Hill Education, New York, USA., ISBN: 9780071604758 , Pages: 754.

Sun, S., Q. Zheng, D. Li and J. Wen, 2009. Long-term atmospheric corrosion behaviour of Aluminium alloys 2024 and 7075 in urban, coastal and industrial environments. Corros. Sci., 51: 719-727.

Vera, R., D. Delgado and B.M. Rosales, 2006. Effect of atmospheric pollutants on the corrosion of high power electrical conductors: Part 1. Aluminium and AA6201 alloy. Corros. Sci., 48: 2882-2900. 